\title{
Workplace Spirituality and Engagement among Faculty Staff versus their Assistants
}

\author{
Hoda A. El-Guindy ${ }^{1} \&$ Basiony M. Basiony ${ }^{2}$. \\ 1. Assist. Prof. of Nursing Administration, Faculty of Nursing, Beni-Suef University, Egypt. \\ 2. Lecturer of Nursing Administration, Faculty of Nursing, Beni-Suef University, Egypt.
}

\begin{abstract}
Background: Work engagement is a positive state of mind characterized by the extent to which employees are vigorous. Spirituality is a sense of wholeness, connectedness at work, and deeper values. Aim: The current study aimed to compare workplace spirituality and engagement among faculty staff versus their assistants. Subject and Methods: A descriptive comparative research design was used. Setting: This study was conducted at faculty of nursing Beni-Suef University. Sample: Convenient sample of all available staff on job during data collection period. (48) Faculty staff members and (79) faculty staff members' assistants were included in the study. Tools: Data were collected using two tools; workplace spirituality questionnaire and work engagement scale. Results: More than three quarters of faculty staff members had high work engagement level while more than two thirds for their assistants, more than two thirds of faculty staff members had high workplace spirituality and majority of their assistants had high level. Conclusion: The current study concluded that there is no significant difference among the perception of the faculty staff members and their assistants regarding workplace spirituality, while there is a significant difference between the perception of the faculty staff and faculty staff assistants regarding work engagement. Recommendations: The study recommends encourage high spirituality of all faculty staff and workers, reward high engaged staff and gives more appreciation, enhance sense of community for all staff and workers, and disseminate organizational values all over the faculty to get more cooperation.
\end{abstract}

\section{Keywords: Faculty Staff Assistants, Faculty Staff Members, Work Engagement \& Workplace Spirituality.}

\section{Introduction}

Workplace spirituality is an experience of interconnectedness, common by all those involved in the work practice, firstly activated by the awareness that each is separately motivated by an internal power, which increases and maintains their wisdom, goodness, creativity, proactivity, sympathy, loyalty, confidence, and courage; consequently, leading to the communal formation of an aesthetically. Motivational atmosphere characterized by a sense of purpose, high ethical principles, acceptance, harmony, confidence, admiration, sympathetic, gratefulness, attention, immersion, usefulness, encouragement, attainment, and perspective, thus establishing an atmosphere of improved group act and overall agreement, and ultimately guiding the institution to become highly productive, and agency accomplished its goals (Afsar \& Badir, 2017).

Workplace spirituality is based on an individual's personal values and philosophy where in, it is expected that an individual need to view themselves as spiritual being whose soul need proper sustenance at work, who experience a sense of purpose and significance in effort, and a sense of connectedness to one another and to their workstation and public at large. Workplace spirituality involves the energy to find one's crucial purpose in life, to improve a strong joining to colleagues and other people associated with work, and to have consistency between one's core beliefs and the values of their institutions (Daniel, 2015).

Workplace spirituality has three important dimensions. The first dimension is meaningful worksignifies the level to which individuals experience a deep sense of meaning and purpose at work. The sense of community is the second dimension which means individuals realize themselves as linked to each other and that there is some type of connection between one's internal self and the internal self of other people. The third and the most important dimension is value alignment- which measures whether or not people experience a strong sense of configuration between their personal values and the organization's mission and purpose (Moran, 2017).

Work engagement is the willingness of an individual to spend his efforts and time beyond the minimum requirements, to commit and work on task or job that is related to his/her position in an organization, in order to ensure organizational success (Roof, 2015). It is the state whereby an individual is enthusiastically involved in her/his role performance while aligning personal targets with the organizational goals. Work engagement is vital for organization and the workers. In the practical world of work, developing engagement among staff is considered as the most essential mission of today's 
institutions. Researches has revealed that job engagement leads to optimistic effects such as less displacement, more organizational commitment, and organizational performance (Mahakul \& Pathi, 2016).

Work engagement is crucial for enterprises and the employees. Work engagement absolutely affects an employee's performance. It permits to showing full potential to the job. It even supports extra-role practice by adopting a practical approach to work. It stimulates workers to go outside their core responsibilities and increase new knowledge. Work engagement includes three core aspects which are: Intellectual engagement - think hard how to do the job better, affective engagement - feel good about doing a job and social engagement - take chances actively to converse with others work-related improvements (Petchsawang \& McLean, 2017).

However, workplace spirituality and engagement both advocates a sense of inclusiveness to each other in their underlying construct. The primary drivers of feeling completeness are identification of oneself with organization's goals and internalization of the organization's values and mission engagement with meaningfulness and joy at work, compassion, trust, well-being of employees through fostering spirituality at work. Moreover, there is a shortage of empirical investigation whether spirituality influences human productivity as asserted by academic researchers and professional consultants (Karanika, et al., 2015).

Faculty members are distributing their knowledge and skills to make the next generation of nursing educators for real practice. They improve lesson strategies, teach courses, appraise educational curricula, supervise students' clinical preparation and serve as role models for their students. They may communicate general courses or focus on specialization. Most faculty teachers have widespread clinical understanding, and many stay caring for patients after becoming educators. Even if they no longer practice, nurse educators must keep up to date their information about new nursing methods and technologies, which retain them on the pioneering of clinical practice (Sulaiman \& Zahoni, 2016).

\section{Significance of the Study}

During the researchers working with their colleagues observed that faculty staff members and their assistants are suffering from high workload, attached to multiple activities and roles because they are often busy with numerous job tasks (e.g., teaching, research, and working with people, budgeting) that are vital to the whole operation of the organization. Stressed staff tends to report warning signs and how it relates to the critical imperative of engagement in the workplace.
Disengaged staff is suffering from job dissatisfaction, low motivation, low workplace spirituality and low morale (Gutermann, et al., 2017). Awareness of workplace spirituality and staff engagement has improved significantly over the last decade among practitioners and scholars. However, even though both issues focus on the significance of the spirit at work, they have appeared independent of each other with little consideration to how they are connected. So, the present study aimed at finding out the relationship between workplace spirituality and work engagement among faculty staff members and their assistants.

\section{Aim of the Study}

The current study aimed to compare workplace spirituality and engagement among faculty staff versus their assistants.

\section{Research Questions}

Q1- What is the difference between faculty staff members and their assistants' perception regarding workplace spirituality?

Q2- What is the difference between faculty staff members and their assistants' perception regarding work engagement?

\section{Subject \& Methods \\ Research design}

A descriptive comparative research design was utilized.

\section{Setting}

The study was conducted at Faculty of Nursing BeniSuef University at all scientific departments namely: Nursing Administration Department, Medical Surgical Nursing Department, Pediatric Nursing Department, Maternity and Newborn Nursing Department, Community Health Nursing Department, and Psychiatric Nursing Department.

\section{Subjects}

Convenient sample of all the available staff on job was subjects for the study. They included two groups, namely; faculty staff members and their assistants' groups a) Faculty staff members group: this group consisted of (48) faculty members divided as follows: nine assistant professors and 39 lecturers, and b) Faculty staff assistants group: This group consisted of 79 faculty staff assistants divided as follows: 32 assistants' lecturers and 47 demonstrators.

\section{Data collection tools}

Data of this study was collected using two tools namely; Workplace Spirituality Questionnaire and Utrecht Work Engagement Scale (UWES).

1-Workplace Spirituality Questionnaire:

It aimed to assess study subjects' perception regarding workplace spirituality. This tool was adapted from Gupta (2014) and consists of two parts: 
Part 1: Demographic sheet: to collect data pertaining demographic characteristics of study subjects such as age, gender, level of education, marital status, and years of experience ....etc.

Part 2: This part included (35) items, divided into four main dimensions: Meaningful work, Sense of community, Organizational values and compassion.

\section{Scoring system}

Each point was scored according to a five point likert scale from 1 (strongly disagree) to 5 (strongly agree). The scores of each point were summed up, converted into percent score and the total divided by the sample size giving a mean score of each point and also the total of all points of each dimension was divided by the number of points in the dimension giving a mean score for the dimension. These mean scores of each point and each dimension were then considered low if $<60 \%$, moderate if $60 \%-75 \%$ and high if $>75 \%$.

2- Utrecht Work Engagement Scale (UWES):

This tool adapted from Shusha \& Abd Elkader (2017). This scale aimed to assess work engagement level. It included 17 items. The scale was divided into three main domains namely vigor, dedication and absorption.

\section{Scoring system}

Each point was scored according to a five point likert scale from 1 (strongly disagree) to 5 (strongly agree). The scores of each point were summed up, converted into percent score and the total divided by the sample size giving a mean score of each point and also the total of all points of each dimension was divided by the number of points in the dimension giving a mean score for the dimension. These mean scores of each point and each dimension were then considered low if $<60 \%$, moderate if $60 \%-75 \%$ and high if $>75 \%$.

\section{Tools validity and reliability}

Face and content validity of the tools was assessed by jury group consisted of seven experts from different nursing faculties. Jury group members judge tools for comprehensiveness, accuracy and clarity in language. Based on their recommendation's correction, addition and/or omission of some items were done.

The study tools were tested for its internal consistency by Cronbach's Alpha. It was 0.827 for workplace spirituality questionnaire and 0.892 for the Utrecht work engagement scale.

\section{Pilot study}

A pilot study was conducted on $10 \%$ of the study subjects. It aimed to evaluate the relevance, clarity and content of the tools used for data collection, validity evaluate time needed for the study subjects to fill tools of the study and find the potential deflects and difficulties that might face researchers and hinder data collection. According to the results of the pilot study, simple modifications were done.

\section{Data collection procedure}

Data collection of the study was started at the beginning of March 2019, and completed by the end of August 2019. Data were collected during morning for faculty of nursing Beni-Suef University for three days weekly including all faculty staff members and their assistants through using study tools by the researchers. An approval of the study subjects was obtained orally after explaining the purpose of the study.

The researchers met faculty staff members and their assistants and explain purpose of the study to them and how to file in the study tools. The completed tools were returned in the same day. Workplace spirituality questionnaire consumed from 20 to 30 minutes to be completed while the work engagement questionnaire from 15 to 20 minutes to be completed. Data collected was anonymous to preserve confidentiality.

\section{Ethical Considerations}

Prior study conduction, the researchers met the study subjects to explain the purpose of the study and to obtain their approval to participate. They were reassured about the anonymity and confidentiality of the collected data, which was used only for the purpose of scientific research. The subjects' right to withdraw from the study at any time was assured. 


\section{Results}

Table (1): Demographic characteristics of Faculty staff members ( $n=48)$.

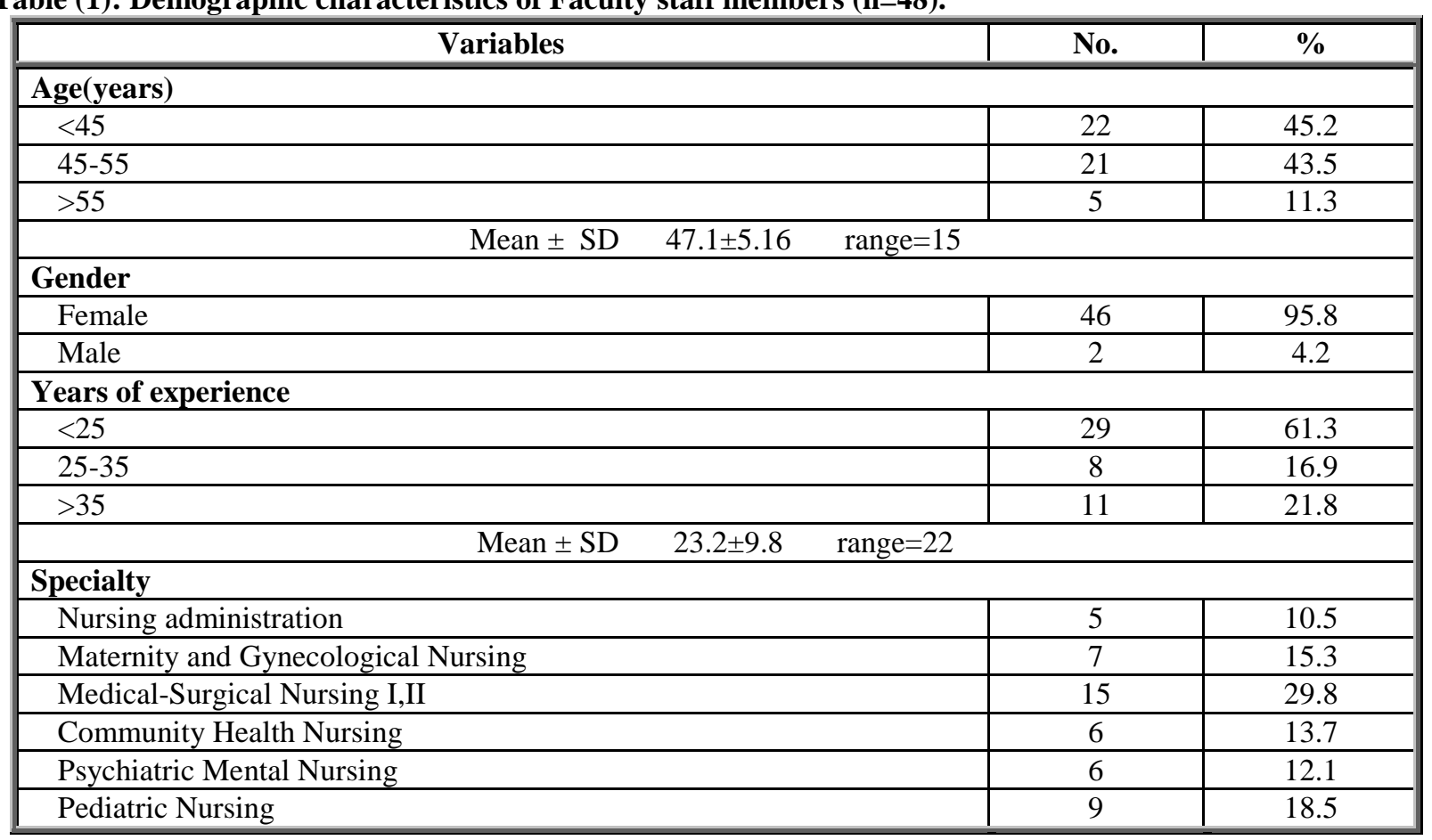

Table (2): Demographic characteristics of Faculty staff assistants (n=78).

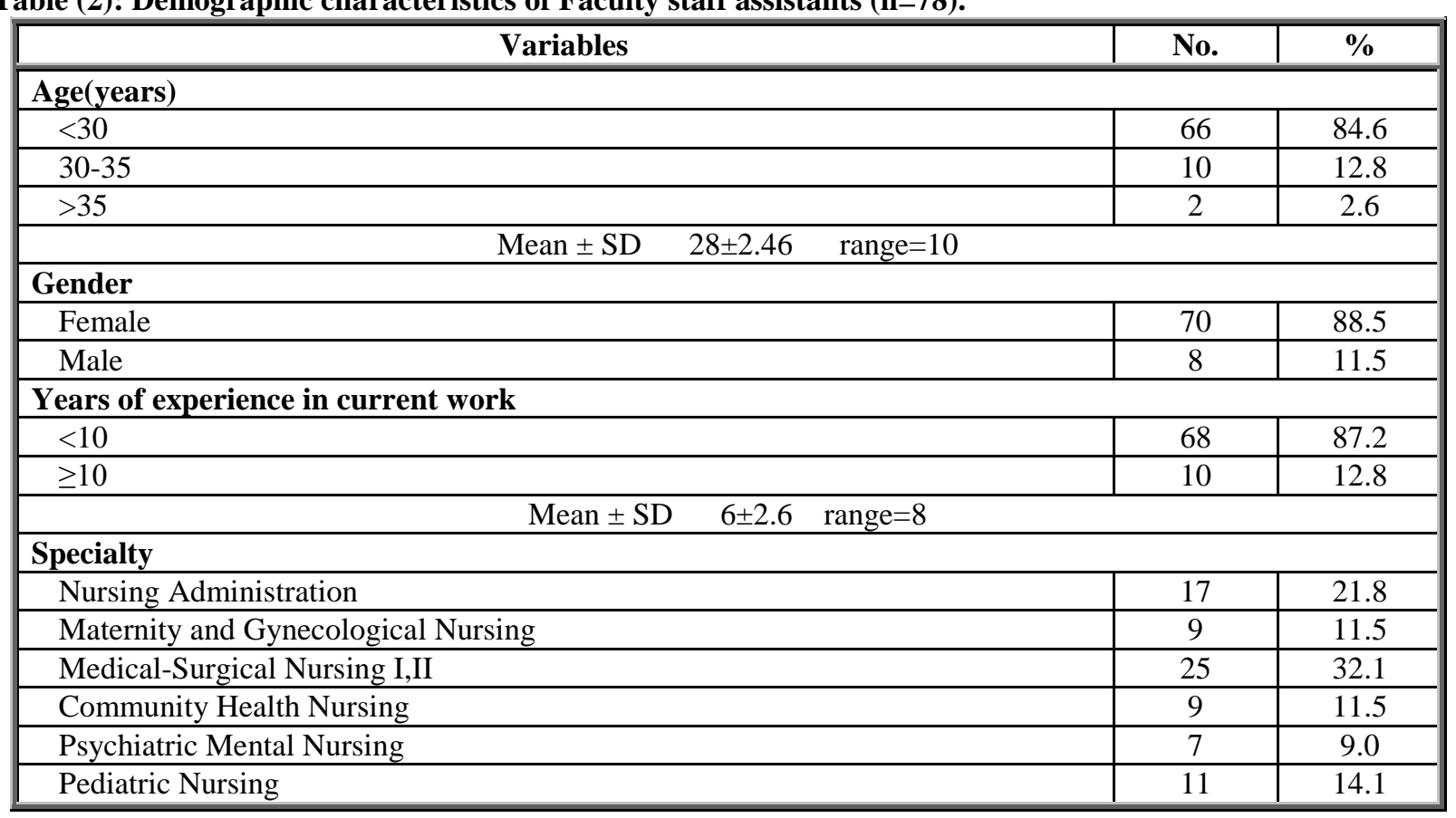


Table (3): Workplace spirituality level among Faculty staff members $(n=48)$.

\begin{tabular}{|c|c|c|c|c|c|c|}
\hline \multirow{2}{*}{ workplace spirituality Dimensions } & \multicolumn{6}{|c|}{ Perception level } \\
\cline { 2 - 7 } & \multicolumn{2}{|c|}{ Low $<\mathbf{6 0 \%}$} & Moderate 60-<75\% & \multicolumn{2}{c|}{ High $\geq \mathbf{7 5 \%}$} \\
\cline { 2 - 7 } & No. & $\mathbf{\%}$ & No. & \% & No. & \% \\
\hline Meaningful work & 2 & 4.1 & 4 & 8.3 & 42 & 87.6 \\
\hline Sense of community & 3 & 6.3 & 6 & 12.5 & 39 & 81.2 \\
\hline Organizational values & 6 & 12.5 & 28 & 58.3 & 14 & 29.2 \\
\hline Compassion & 1 & 2.1 & 2 & 4.2 & 45 & 93.7 \\
\hline
\end{tabular}

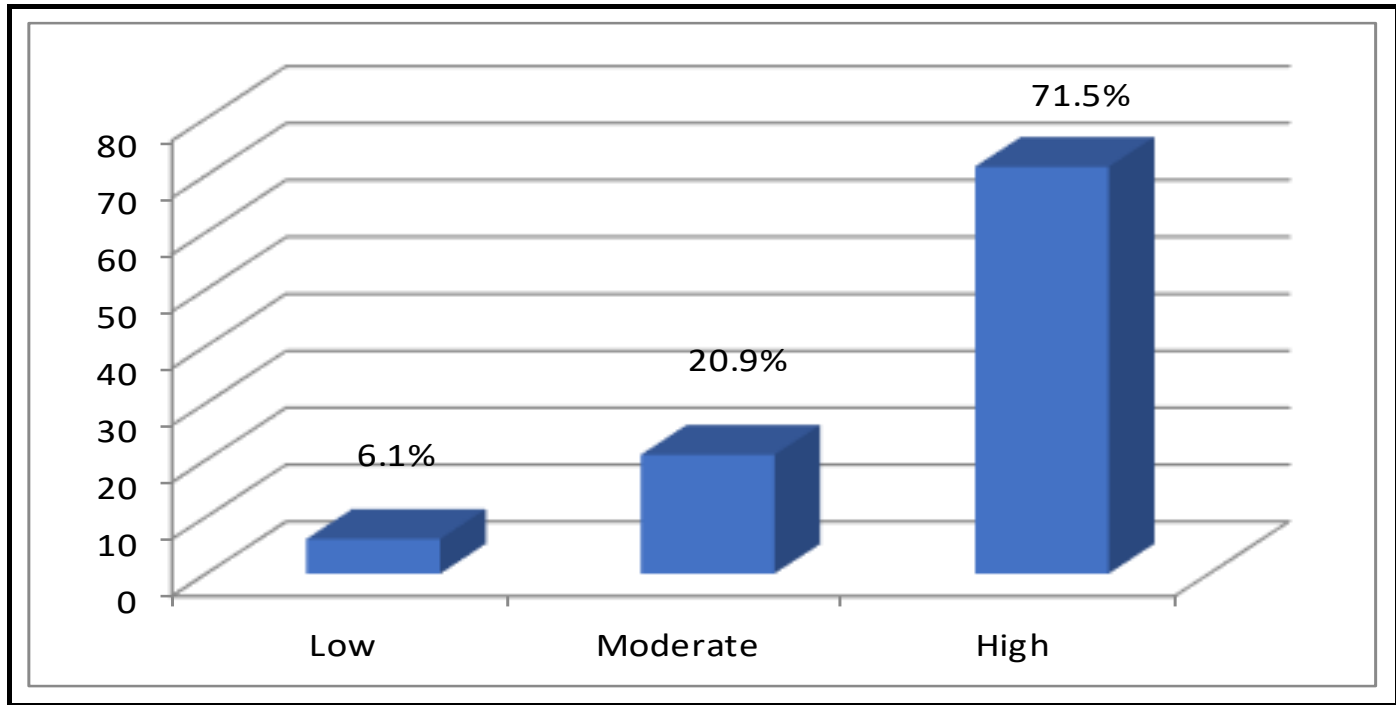

Figure (1): Total perception level toward workplace spirituality among faculty staff members.

Table (4): work engagement level among faculty staff members $(n=48)$.

\begin{tabular}{|c|c|c|c|c|c|c|}
\hline \multirow{2}{*}{ work engagement dimensions } & \multicolumn{6}{|c|}{ Work engagement level } \\
\cline { 2 - 7 } & \multicolumn{2}{|c|}{ Low $<\mathbf{6 0 \%}$} & Moderate 60<75\% & \multicolumn{2}{c|}{ High $\geq \mathbf{7 5 \%}$} \\
\cline { 2 - 7 } & No. & $\mathbf{\%}$ & No. & $\mathbf{\%}$ & No. & $\mathbf{\%}$ \\
\hline Viger & 2 & 4.1 & 10 & 20.9 & 36 & 75 \\
\hline Dedication & 3 & 6.3 & 5 & 10.4 & 40 & 83.3 \\
\hline Absorption & 3 & 6.3 & 10 & 20.9 & 36 & 72.8 \\
\hline
\end{tabular}

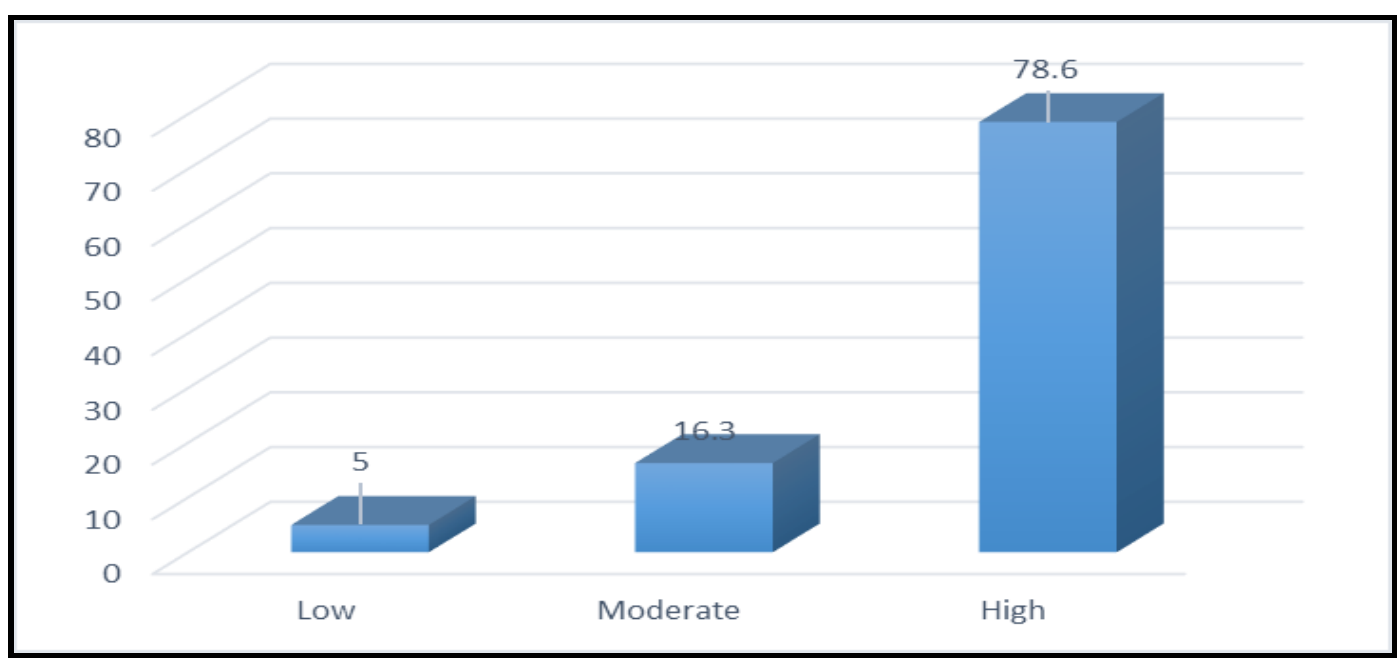

Figure (2): work engagement level among Faculty staff members. 
Table (5): Workplace spirituality level among faculty staff assistants $(n=79)$.

\begin{tabular}{|c|c|c|c|c|c|c|}
\hline \multirow{2}{*}{$\begin{array}{c}\text { workplace spirituality } \\
\text { Dimensions }\end{array}$} & \multicolumn{5}{|c|}{ workplace spirituality level } \\
\cline { 2 - 7 } & \multicolumn{2}{|c|}{ Low $<\mathbf{6 0 \%}$} & Moderate 60<75\% & \multicolumn{2}{c|}{ High $\geq \mathbf{7 5 \%}$} \\
\cline { 2 - 7 } & No. & \% & No. & \% & No. & \% \\
\hline Meaningful work & 2 & 2.9 & 7 & 9.5 & 68 & 87.6 \\
\hline Sense of community & 3 & 4.4 & 10 & 13.4 & 64 & 82.3 \\
\hline Organizational values & 4 & 5.7 & 17 & 22.4 & 56 & 71.7 \\
\hline Compassion & 1 & 1.2 & 2 & 2.5 & 75 & 96.4 \\
\hline
\end{tabular}

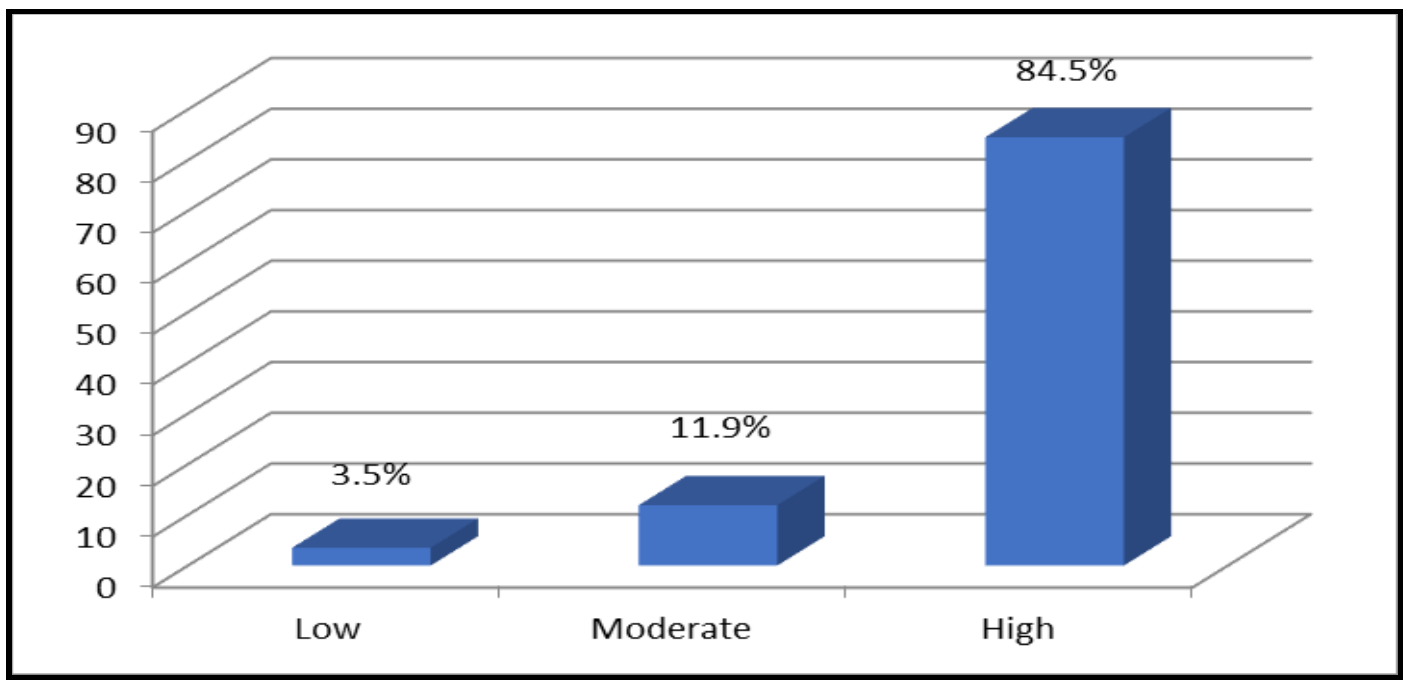

Figure (3): Workplace spirituality level among faculty staff assistants.

Table (6): Work engagement level among faculty staff assistants (n=79).

\begin{tabular}{|c|c|c|c|c|c|c|}
\hline \multirow{2}{*}{$\begin{array}{c}\text { work engagement } \\
\text { Dimensions }\end{array}$} & \multicolumn{6}{|c|}{ work engagement level } \\
\cline { 2 - 7 } & \multicolumn{2}{|c|}{ Low $<\mathbf{6 0 \%}$} & \multicolumn{2}{c|}{ Moderate 60<75\% } & \multicolumn{2}{c|}{ High $>\mathbf{7 5 \%}$} \\
\cline { 2 - 7 } & No. & \% & No. & \% & No. & \% \\
\hline Viger & 6 & 8.1 & 22 & 28.2 & 49 & 63.7 \\
\hline Dedication & 7 & 9.22 & 14 & 17.94 & 56 & 72.76 \\
\hline Absorption & 7 & 10.0 & 19 & 25.2 & 50 & 64.7 \\
\hline
\end{tabular}

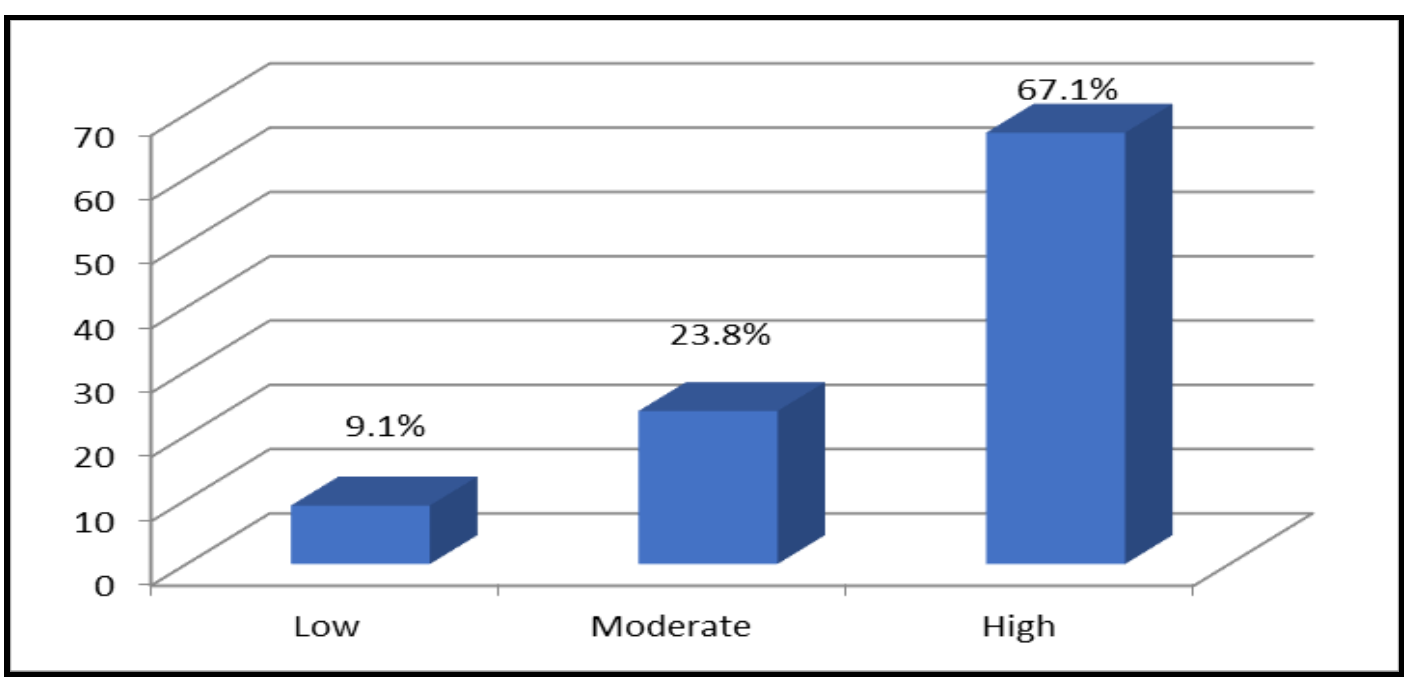

Figure (4): Work engagement level among faculty staff assistants. 
Table (7): Mean differences between faculty staff members and their assistants regarding workplace spirituality.

\begin{tabular}{|l|c|c|c|c|c|c|}
\hline \multirow{2}{*}{ workplace spirituality Dimensions } & \multicolumn{2}{|c|}{$\begin{array}{c}\text { Faculty staff } \\
\text { members }\end{array}$} & \multicolumn{2}{c|}{$\begin{array}{c}\text { Faculty staff } \\
\text { assistants }\end{array}$} & \multirow{2}{*}{ t-value } & \multirow{2}{*}{ p-value } \\
\cline { 2 - 5 } & Mean & SD & Mean & SD & & \\
\hline Meaningful work & 4.20 & 0.50 & 4.22 & 0.57 & 0.19 & 0.84 \\
\hline Sense of community & 4.05 & 0.50 & 4.06 & 0.63 & 0.16 & 0.86 \\
\hline Organizational values & 3.85 & 0.59 & 3.81 & 0.64 & 0.45 & 0.65 \\
\hline Compassion & 4.32 & 0.59 & 4.45 & 0.50 & 1.54 & 0.12 \\
\hline Total spirituality in workplace & 4.07 & 0.43 & 4.13 & 0.49 & 0.98 & 0.32 \\
\hline
\end{tabular}

Table (8): Mean differences between faculty staff members and their assistants regarding work engagement.

\begin{tabular}{|c|c|c|c|c|c|c|}
\hline \multirow{2}{*}{ work engagement } & \multicolumn{2}{|c|}{$\begin{array}{c}\text { Faculty } \\
\text { staff members }\end{array}$} & \multicolumn{2}{c|}{$\begin{array}{c}\text { Faculty staff } \\
\text { assistants }\end{array}$} & \multirow{2}{*}{ t-value } & \multirow{2}{*}{ p-value } \\
\cline { 2 - 5 } & Mean & SD & Mean & SD & & \\
\hline Viger & 3.94 & 0.63 & 3.70 & 0.72 & 2.45 & $0.015^{*}$ \\
\hline Dedication & 4.09 & 0.65 & 3.91 & 0.83 & 1.64 & 0.1 \\
\hline Absorption & 4.00 & 0.64 & 3.74 & 0.72 & 2.74 & $0.007^{*}$ \\
\hline Total work engagement & 4.01 & 0.59 & 3.78 & 0.70 & 2.43 & $0.016^{*}$ \\
\hline
\end{tabular}

(*) statistically significant at p-value $<0.05$

Table (9): Correlation between workplace spirituality and work engagement among faculty staff members.

\begin{tabular}{|c|c|c|c|c|c|c|c|c|c|c|}
\hline \multirow{3}{*}{$\begin{array}{c}\text { Work } \\
\text { engagement }\end{array}$} & \multicolumn{10}{|c|}{ Workplace spirituality } \\
\hline & \multicolumn{2}{|c|}{$\begin{array}{c}\text { Meaningful } \\
\text { work }\end{array}$} & \multicolumn{2}{|c|}{$\begin{array}{c}\text { Sense of } \\
\text { community }\end{array}$} & \multicolumn{2}{|c|}{$\begin{array}{c}\text { Organizational } \\
\text { values }\end{array}$} & \multicolumn{2}{|c|}{ Compassion } & \multicolumn{2}{|c|}{ Total } \\
\hline & $\mathbf{R}$ & $\mathrm{p}$ & $\mathbf{R}$ & $\mathrm{P}$ & $\mathbf{r}$ & $\mathrm{P}$ & $\mathbf{R}$ & $\mathrm{p}$ & $\mathbf{r}$ & $\mathrm{p}$ \\
\hline Viger & .34 & $.0001 *$ & .35 & $.0001 *$ & .23 & $.008^{*}$ & .19 & $.03 *$ & .36 & $.0001 *$ \\
\hline Dedication & .36 & $.0001 *$ & .38 & $.0001 *$ & .2 & $.02 *$ & .15 & .08 & .35 & $.0001 \%$ \\
\hline Absorption & .34 & $.0001 *$ & 36 & $.0001 *$ & .2 & $.02 *$ & .18 & $.04 *$ & .35 & $.0001 *$ \\
\hline Total & .39 & $.0001 *$ & .39 & $.0001 *$ & .22 & $.01 *$ & .18 & $.03 *$ & .38 & $.0001 *$ \\
\hline
\end{tabular}

(*) statistically significant at p-value $<0.05$

Table (10): Correlation between workplace spirituality and work engagement among faculty staff assistants.

\begin{tabular}{|c|c|c|c|c|c|c|c|c|c|c|}
\hline \multirow{3}{*}{$\begin{array}{c}\text { Work } \\
\text { engagement }\end{array}$} & \multicolumn{10}{|c|}{ Workplace spirituality } \\
\hline & \multicolumn{2}{|c|}{$\begin{array}{c}\text { Meaningful } \\
\text { work }\end{array}$} & \multicolumn{2}{|c|}{$\begin{array}{c}\begin{array}{c}\text { Sense of } \\
\text { community }\end{array} \\
\end{array}$} & \multicolumn{2}{|c|}{$\begin{array}{c}\text { Organizational } \\
\text { values }\end{array}$} & \multicolumn{2}{|c|}{ Compassion } & \multicolumn{2}{|c|}{ Total } \\
\hline & $\mathbf{R}$ & $\mathrm{P}$ & $\mathbf{R}$ & $\mathrm{P}$ & $\mathbf{r}$ & $\mathrm{p}$ & $\mathbf{R}$ & $\mathrm{p}$ & $\mathbf{R}$ & $\mathrm{p}$ \\
\hline Viger & .41 & $.0001 *$ & .34 & $.001 *$ & .22 & .06 & .11 & .34 & .33 & $.003 *$ \\
\hline Dedication & .35 & $.001 *$ & .41 & $.0001 *$ & .32 & $.004 *$ & .16 & .15 & .38 & $.001 *$ \\
\hline Absorption & .38 & $.001 *$ & .8 & $.001 *$ & .3 & $.007 *$ & .12 & .26 & .36 & $.001 *$ \\
\hline Total & .41 & $.0001 *$ & .42 & $.0001 *$ & .3 & $.006 *$ & .14 & .2 & .39 & $.001 *$ \\
\hline
\end{tabular}

(*) statistically significant at $p$-value $<0.05$

Table (1): Clarifies that, $95.8 \%$ of the studied faculty staff members were females, $45.2 \%$ had age less than 45 years, $61.3 \%$ had less than 25 years of experience, and $29.8 \%$ specialized in Medical-Surgical Nursing.

Table (2): Clarifies that $84.6 \%$ of the studied faculty staff assistants had age $<30$ years, $88.5 \%$ were females, $87 \%$ had less than 20 years of experience, $32 \%$ of them were specialized Medical-Surgical Nursing.

Table (3): Clarifies that the majority of faculty staff members had high perception level for the compassion dimension and meaningful work dimension with (93.7\% and $87.6 \%$ respectively).

Figure (1): Shows that the total perception level of faculty staff members toward workplace spirituality was high with $71.5 \%$ while $20.9 \%$ had moderate level of perception and only $6.1 \%$ had low perception.

Table (4): Clarifies that the majority of faculty staff members had high level of perception for the dedication dimension with $83.3 \%$ while the lowest 
level was for the absorption with only $72.8 \%$ high and $20.9 \%$ moderate.

Figure (2): Explains $78.6 \%$ of faculty staff members had high work engagement level while only $5 \%$ of them had low work engagement level.

Table (5): Clarifies that the majority of faculty staff assistants had high level of perception for the compassion dimension with $96.4 \%$ while the lowest perception was for the organizational values with only $71.7 \%$ high and $22.4 \%$ moderate.

Figure (3): Shows that the total perception level of faculty staff assistants toward workplace spirituality was high with $84.5 \%$ while $11.9 \%$ had moderate level of perception and only $3.5 \%$ had low perception.

Table (6): Clarifies that the majority of faculty staff assistants had high level of perception for the dedication dimension with $72 \%$ while the lowest perception was for the viger with only $63.7 \%$ high and $28 \%$ moderate.

Figure (4): Shows that the total perception level of faculty staff assistants toward work engagement was high with $67.1 \%$ while $23.8 \%$ had moderate level of perception and only $9.1 \%$ had low perception.

This Table (7): Shows that there is no significant difference between the perception of the faculty staff members and faculty staff assistants regarding workplace spirituality but perception of the faculty staff assistants is higher than faculty staff members for all dimensions except organizational values dimension.

Table (8): Shows that there are statistically significant difference between the perception of the faculty staff members and faculty staff assistants regarding work engagement where the perception of the faculty staff is higher than faculty staff assistants for all dimensions.

Table (9): Shows that there are highly statistically significant direct positive correlation between all dimensions of workplace spirituality and all dimensions of work engagement.

Table (10): Shows that there are statistically significant high positive direct correlation between all the dimensions of workplace spirituality and all the dimensions of work engagement except compassion dimension which is not correlated with work engagement.

\section{Discussion}

Regarding the comparison between faculty staff members and faculty staff assistants' perception regarding workplace spirituality dimensions and work engagement, the result revealed that the perception of the faculty staff assistants regarding workplace spirituality is higher than perception of faculty staff for all dimensions except organizational values dimensions. While the perception of the faculty staff regarding work engagement is higher than perception of faculty staff assistants for all dimensions. Concerning work engagement, there is a significant difference between the perception of the faculty staff and faculty staff assistants regarding work engagement where the perception of the faculty staff is higher than perception of faculty staff assistants for all dimensions.

This result may be due to more value is experienced by faculty staff members, this value affects their spirituality positively and make them feel better, also high spirituality of faculty staff assistants given from their hope and dreams for better future.

In the same line, Gupta \& Mikkilineni, (2018) who revealed that workplace spirituality teaches past practices of inter-connectivity and a sense of confidence among individuals who are a part of a specific work procedure, which consequently initiate supportive feelings and lead to an inclusive organizational culture that is driven by motivation, demonstrated by a positive response, and agreement and harmony among the individuals, and affect the younger workers than others and improve their spirituality.

While, Abdelrazek, et al., (2016) concluded that there is no principal leadership style/s whether the traditional or innovative that could be respectable, but when combined with ordinary level of work engagement revealed no significant correlations. This means that work engagement level should be enhanced mostly based on to vigor and dedication upgrading actions.

Regarding Correlation between workplace spirituality and work engagement among faculty staff and their assistants, there was a statistically significant high positive direct correlation between all the dimensions of workplace spirituality and all the dimensions of work engagement except compassion which is not correlated with work engagement. This result may be due to the positive effect of work spirituality on employees' work engagement. The more work spirituality the more work engagement.

The same result was reported by Roof, (2015), Paul, et al., (2016) who explained that, the spirituality has now become an effective tool to handle stress related issues, for overcoming work problems, and promoting psychological growth. It has direct positive correlation with work engagement. These results are in congruence with the findings of Hakanen et al., (2006) who found a negative relationship between workplace stressors and work engagement.

Similar finding was reported with Chung \& Angeline, (2010) studied on the intermediating nature of work engagement among working adults in Malaysia. The investigator stated that work 
engagement had incompletely mediated the resources-performance connections. Moreover, Bakker \& Bal, (2010) studied the weekly work engagement and practice of Dutch teachers. The investigator indicated that work engagement act as a mediator between resources and performance.

Additionally, Büssing, et al., (2015) reported that work engagement had considered as a probable mediator between social resources and performance of the group members. It illustrates that the mediating role of work engagement is not just limited to individual level. Thus, it has been predicted through the findings of preceding and existing studies that, work engagement has a vital role in the employees' performance, improvement of process and the connection between resources, work engagement and job performance.

Lastly, Individuals who have positive attitudes towards their organizations do not essentially work harder. On the other hand, individuals who interested in problem solving and perform confidently are not necessarily loyal to their organization. That means people need to influence an aspect of engagement if motivated for a specific result. Although engagement is invented of many aspects, there is one central component that managers and organizations need to hold and take truly: employees need to sense that their organization is honestly interested in them.

\section{Conclusion}

The current study concluded that there is no significant difference between the perception of the faculty staff and faculty assistants regarding workplace spirituality, while there is a significant difference between the perception of the faculty staff and faculty staff assistants regarding work engagement where the perception of the faculty staff is higher than perception of faculty staff assistants for all dimensions.

\section{Recommendations}

In the light of the findings of the present study, the following are recommended

- Reward high engaged staff and gives them more appreciation.

- Enhance sense of community for all staff and workers.

- Disseminate organizational values all over the faculty to get more cooperation.

- Periodical assessment of workplace spirituality of faculty staff members and their assistants.

- Periodical assessment of workplace spirituality of faculty employees.

\section{References}

- Abdelrazek, E., Hezma, A., El-Khodary, A., \& Elzayat, A., (2016): Spectroscopic studies and thermal properties of PCL/PMMA biopolymer blend. Egyptian Journal of Basic and Applied Sciences, 3(1), 10-15.

- Afsar, B., \& Badir, Y., (2017): Workplace spirituality, perceived organizational support and innovative work behavior: The mediating effects of person-organization fit. Journal of workplace Learning, 29(2), 95-109.

- Bakker, A., \& Bal, M., (2010): Weekly work engagement and performance: A study among starting teachers; Journal of occupational and organizational psychology, 83(1), 189-206.

- Büssing, A., Lötzke, D., Glöckler, M., \& Heusser, P., (2015): Influence of spirituality on cool down reactions, work engagement, and life satisfaction in anthroposophic health care professionals. Evidence-Based Complementary and Alternative Medicine, 2015.

- Chung, N., \& Angeline, T., (2010): Does work engagement mediate the relationship between job resources and job performance of employees. African Journal of Business Management, 4(9), 1837-1843.

- Daniel, J., (2015): Workplace spirituality and stress: evidence from Mexico and US. Management Research Review, 38(1), 29-43.

- Gupta, M., \& Mikkilineni, S., (2018): Spirituality and Employee Engagement at Work. The Palgrave Handbook of Workplace Spirituality and Fulfillment, 1-15.

- Gupta, R., (2014): Spirituality and Innovative Behavior in Teams: Examining the Mediating Role of Team Learning. IIMB Management Review.

- Gutermann, D., LehmannWillenbrock, N., Boer, D., Born, M., \& Voelpel, S., (2017): How leaders affect followers' work engagement and performance: Integrating leader- member exchange and crossover theory. British Journal of Management, 28(2), 299-314.

- Hakanen, J., Bakker, A., \& Schaufeli, W., (2006): Burnout and work engagement among teachers. Journal of school psychology, 43(6), 495513.

- Karanika, M., Duncan, N., Pontes, H., \& Griffiths, M., (2015): Organizational identification, work engagement, and job satisfaction. Journal of Managerial Psychology, 30(8), 1019-1033.

- Mahakul, P., \& Pathi, S., (2016): A Study on A Developed Theory of Stress Control and Stress Relief through Spirituality. International Journal in Management \& Social Science, 4(12), 72-81. 
- Moran, R., (2017): Workplace spirituality in law enforcement: a content analysis of the literature. Journal of Management, Spirituality \& Religion, 14(4), 343-364.

- Paul, M., Dutta, A., \& Saha, P., (2016): Improving Organizational Effectiveness through Workplace Spirituality a41144nd Organizational Citizenship Behaviour: A Conceptual Review. In Globsyn management conference 2015 (Vol. 1, p. 79). Allied Publishers.

- Petchsawang, P., \& McLean, G., (2017): Workplace spirituality, mindfulness meditation, and work engagement. Journal of Management, Spirituality \& Religion, 14(3), 216-244.

- Roof, R., (2015): The association of individual spirituality on employee engagement: The spirit at work. Journal of Business Ethics, 130(3), 585-599.

- Shusha, A., \& Abdelkader, A., (2016): Work engagement in higher education in Egypt: the influence on academic work performance. International Journal of Business Performance Management, 17(2), 132-146.

- Sulaiman, W., \& Zahoni, N., (2016): Validation of the Utrecht Work Engagement Scale (UWES) in the Malaysian context. International Journal of Social Science and Humanity, 6(9), 672. 